\title{
Disability, Mortality and Causes of Death in a 19th-Century Swedish Population
}

By Lotta Vikström, Sören Edvinsson and Erling Häggström Lundevaller

To cite this article: Vikström, L., Edvinsson, S. \& Häggström Lundevaller, E. (2021). Disability, Mortality and Causes of Death in a 19th-Century Swedish Population. Historical Life Course Studies, 10, 151-155. https://doi.org/10.51964/hlcs9585

\section{HISTORICAL LIFE COURSE STUDIES}

Not Like Everybody Else.

Essays in Honor of Kees Mandemakers

VOLUME 10, SPECIAL ISSUE 3

2021

GUEST EDITORS

Hilde Bras

Jan Kok

Richard L. Zjjdeman 


\section{HISTORICAL LIFE COURSE STUDIES}

Historical Life Course Studies is the electronic journal of the European Historical Population Samples Network (EHPSNet). The journal is the primary publishing outlet for research involved in the conversion of existing European and nonEuropean large historical demographic databases into a common format, the Intermediate Data Structure, and for studies based on these databases. The journal publishes both methodological and substantive research articles.

\section{Methodological Articles}

This section includes methodological articles that describe all forms of data handling involving large historical databases, including extensive descriptions of new or existing databases, syntax, algorithms and extraction programs. Authors are encouraged to share their syntaxes, applications and other forms of software presented in their article, if pertinent, on the openjournals website.

\section{Research articles}

This section includes substantive articles reporting the results of comparative longitudinal studies that are demographic and historical in nature, and that are based on micro-data from large historical databases.

Historical Life Course Studies is a no-fee double-blind, peer-reviewed open-access journal supported by the European Science Foundation (ESF, http://www.esf.org), the Scientific Research Network of Historical Demography (FWO Flanders, http://www.historicaldemography.be) and the International Institute of Social History Amsterdam (IISH, http://socialhistory.org/). Manuscripts are reviewed by the editors, members of the editorial and scientific boards, and by external reviewers. All journal content is freely available on the internet at https://openjournals.nl/index.php/hlcs.

\section{Co-Editors-In-Chief:}

Paul Puschmann (Radboud University) \& Luciana Quaranta (Lund University)

hislives@kuleuven.be

The European Science Foundation (ESF) provides a platform for its Member Organisations to advance science and explore new directions for research at the European level. Established in 1974 as an independent non-governmental organisation, the ESF currently serves 78 Member Organisations across 30 countries. EHPS-Net is an ESF Research Networking Programme.

The European Historical Population Samples Network (EHPS-net) brings together scholars to create a common format for databases containing non-aggregated information on persons, families and households. The aim is to form an integrated and joint interface between many European and non-European databases to stimulate comparative research on the micro-level.

Visit: http://www.ehps-net.eu.
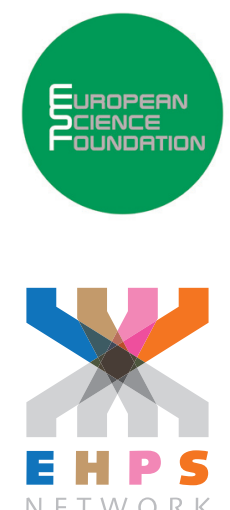


\title{
Disability, Mortality and Causes of Death in a 19th-Century Swedish Population
}

\author{
Lotta Vikström \\ Centre for Demographic and Ageing Research (CEDAR), Umeå University \\ Sören Edvinsson \\ Centre for Demographic and Ageing Research (CEDAR), Umeå University \\ Erling Häggström Lundevaller \\ Centre for Demographic and Ageing Research (CEDAR), Umeå University
}

\begin{abstract}
Our study aims to find how disability affected human health in historical time through an examination of individuals' mortality risks and death causes. Swedish parish registers digitized by the Demographic Data Base (DDB) enable us to account for a relatively high number of persons reported to have disabilities, and to compare them with a group of non-disabled cases. The findings concern a 19th-century population of 35,610 individuals in the Sundsvall region, Sweden, and show that disability increased the premature mortality risk substantially. Disability seems to have jeopardized men's survival in particular, and perhaps due to gendered expectations concerning the type of work men and women became less able to perform when disabled. Our study of death causes indicates that their deaths were less characterized by infectious diseases than among the non-disabled group, as a possible consequence of lower exposure to infections due to the way in which disability could impede opportunities for interaction with peers in the community. In all, our mortality findings suggest that disability was associated with poor living conditions and limited possibilities to participate in work and social life, which further tend to have accumulated across life and resulted in ill health indicated by premature death.
\end{abstract}

Keywords: Disability, Gender, Death causes, Mortality, Sweden

e-ISSN: $\quad$ 2352-6343

DOI article: $\quad$ https://doi.org/10.51964/hlcs9585

The article can be downloaded from here.

(C) 2021, Vikström, Edvinsson, Häggström Lundevaller

This open-access work is licensed under a Creative Commons Attribution 4.0 International License, which permits use, reproduction \& distribution in any medium for non-commercial purposes, provided the original author(s) and source are given credit. See http://creativecommons.org/licenses/. 
Historically, little is known about how disability shaped human health and life. Reports and research from the present day show that disability tends to jeopardize people's health status and to cause them to occupy a more vulnerable position in society (e.g. EC Eurostat, 2017; Schur, Kruse, \& Blanck, 2013; UN Factsheet, 2020). Our study goes 150-200 years back in time with the aim of finding out how disability affected individuals' health through an examination of their mortality and causes of death. We are working on a thorough analysis to be published in due course; the present study is restricted to a descriptive scrutiny of the distribution of causes of death. Swedish parish registers digitized by the Demographic Data Base (DDB) enable us to account for a relatively high number of persons reported to have disabilities, and to compare them with a group of non-disabled.

\section{AREA, DATA AND DEFINITIONS}

The data originate from the 19th-century parish registers of the Sundsvall region, retrieved from the DDB's POPUM database, Umeå University, Sweden. From a selection of 18th- and 19th-century parishes, the DDB registers contain records of birth and baptism, marriage, migration, death and burial, catechetical examination records, all of which are linked on an individual level, thus showing demographic data summarized for each parishioner (Westberg, Engberg, \& Edvinsson, 2016). In these records, the ministers made remarks concerning parishioners' impairments (Iytesmarkeringar), which help us identify and define disabilities. Consequently, we can reconstruct the lives of disabled people and use life-course analysis. Although it is difficult to know how severe or painful these impairments were, they show commonly used terms in the historical context concerning health conditions regarded as limiting people's physical and mental functions (Haage, 2017). Hence, 'disability' was socially constructed in relation to a status perceived to be 'normal' or 'healthy' at the time, here viewed through the eyes of the parish minister. We categorized the impairments into three groups: sensory (visual or hearing defects, denoted by the terms 'blind' or 'deaf mute'), physical (bodily defects, 'cripple'), and mental disabilities ('idiocy', 'insanity').'

Our dataset focuses on the people described by ministers as disabled in the age range 15-34 $(\mathrm{N}=504)$, whom we then follow for a maximum of 18 years. This 'observation window' works to define and estimate premature mortality ( $<54$ years of age) if the event of death occurred during our follow-up, and then we take a closer look at the causes of death. The DDB digitization further allows us to construct a control group that we observe in the same way. It includes parishioners who did not have any impairments reported in the same age span (15-34) and lived in the same time-space context (i.e. the 19th-century Sundsvall region) as the disabled cases. This means that the entire dataset includes a population of 35,610 individuals, all of whom were between 15 and 34 years old at the start of observation.

\section{RESULTS: MORTALITY AND DEATH CAUSES}

Figure 1 plots the premature mortality risks ( $<54$ years of age). The results reveal that disabled men ran the highest risk of dying early in life. Even though disability increased women's mortality as well, the gap between them and the curves of non-disabled women is smaller than the gap found between their male counterparts. Hence, the survival rate was the lowest for disabled men compared to all other groups. Our study does not show the influence of other factors on the mortality risks since this is discussed in a previous study by two of us (Haage, Häggström Lundevaller, \& Vikström, 2016). It confirms that disability more than halved survival chances overall and was statistically significant. Men and all who had mental disabilities experienced the highest mortality risks, though, followed by those with physical and sensory disabilities respectively.

$1 \quad$ These disability concepts were those commonly used in 19th-century society and in the parish registers employed in our study. Although these concepts may be offensive due to the derogatory meaning they carry today, we have no intention to offend anyone. 
Figure $1 \quad$ Plotted cumulative hazards showing the mortality risk by disability and gender in the Sundsvall region 1835-1892

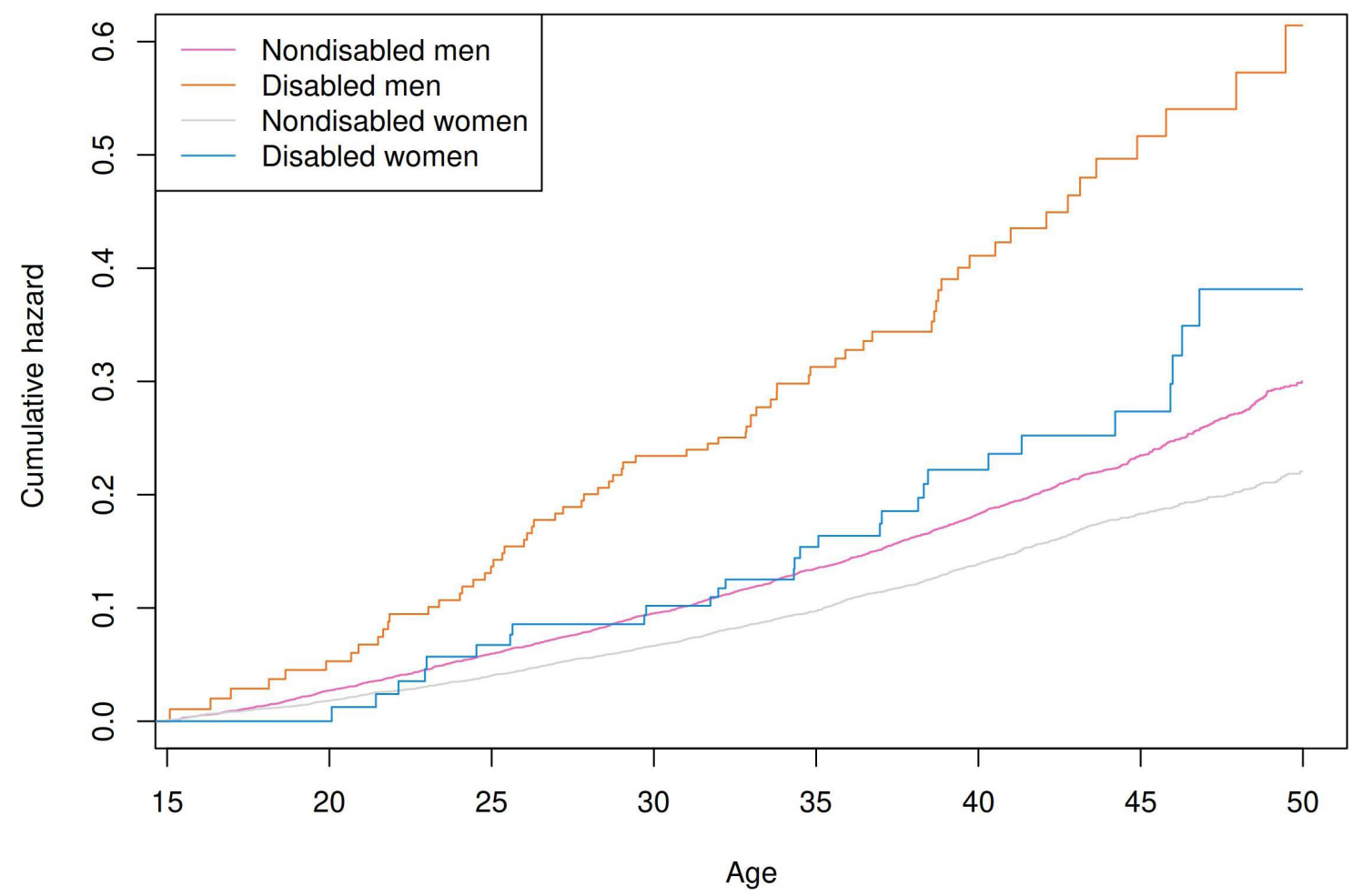

Source: Digitized parish registers, the Sundsvall region, Demographic Data Base (DDB), Umea University, Sweden (Haage, Häggström Lundevaller \& Vikström, 2016).

Now, what did those who passed away during our follow-up die from? As the causes of death are in general under-reported in Swedish parish registers and document symptoms rather than actual death causes, the cause is difficult to interpret even when reported (Edvinsson, 1992). However, it appears that this underregistration was less common among the young adults we are studying, probably because premature death among this group was more surprising than among infants and the elderly. Across the entire dataset, the ministers made notations giving information about death causes in about $60 \%$ of the total number of death cases $(N=2,702)$, albeit to a lower extent $(50 \%)$ in the small group of disabled people (in 50 out of 99 death cases). A comparison with another study (Edvinsson, 1992) of the almost complete reporting of death causes among adults in the town of Sundsvall suggests that the causes under-reported in this study were primarily made up of infectious diseases and 'other diseases'. Table 1 shows the relative distribution of the most frequently reported death causes among the disabled people and the controls according to a historically adapted version of the ICD-10 classification system (WHO, 2004). Although there are no statistically significant differences between the two groups, a couple of interesting things stand out concerning the cause of death pattern. First, compared to the control group, mortality among disabled people was less characterized by infectious diseases ( $26 \%$ vs. $17 \%$ ), such as tuberculosis, typhoid fever, smallpox and cholera. Second, the proportion of violent death causes (e.g. murder, suicide, accidents, drowning, poisoning) suggests that disabled people were not subject to such fatalities to any exceptional extent. Hence, their excess mortality was probably due to respiratory diseases and other diseases, representing a variety of chronic illnesses. The higher proportion of unknown causes among disabled people indicate there was a lower degree of interest in their health conditions and mortality than in those of others. 
Table 1

Relative distribution of frequent death causes by disease groups among individuals who died during observation: comparison between the disabled and non-disabled group

\begin{tabular}{lccc}
\hline & \multicolumn{2}{c}{ Characteristics of the individuals } & Total \\
\hline Disease categories & Disabled (\%) & Non-disabled (\%) & N \\
\hline Infectious diseases & 17.2 & 26.4 & 705 \\
Respiratory diseases & 8.1 & 7.9 & 214 \\
Violent death causes & 7.1 & 10.0 & 266 \\
Other diseases & 17.2 & 17.2 & 465 \\
Unknown/unspecified & 50.5 & 38.5 & 1,052 \\
\hline Total \% & 100 & 100 & 100 \\
Total (N) & $(99)$ & $(2,603)$ & $(2,702)$ \\
\hline
\end{tabular}

Source: Digitized parish registers, the Sundsvall region, Demographic Data Base (DDB), Umeå University, Sweden.

Comments: Disease categories according to the ICD-10-Code Classification where the most frequent types of disease causes reported for individuals are accounted for.

\section{CONCLUDING REMARKS}

The aim of this study was to contribute knowledge on how disability has influenced people's health and death historically, making use of micro-level parish registers digitized by the DDB. Our findings concern a 19th-century population of 35,610 individuals in the Sundsvall region, Sweden, and show that disability increased the mortality risk substantially. It seems as if disability affected the survival chances of men to a considerable extent, perhaps because it made them less able to fulfil their expectations and become major providers through income from rough work in agriculture or in factories. Women were primarily expected to work within the domestic or service sector, occupations that impairments might not have hindered them from following to some extent. From our previous studies based on the parish registers, we know that disability significantly decreased young people's chances of finding a job, even if it did not markedly change the types of occupation they took up. While disabled men experienced $50 \%$ lower occupational chances compared to their non-disabled counterparts or even $70 \%$ lower in the case of mental disorder, disability did not impede women's job chances as much (Vikström, Häggström Lundevaller, Junkka, \& Haage, 2019). Furthermore, disability halved the marital chances of both men and women (Haage, 2017). The negative association between disability and the chances in the labor market as well as in the marriage market likely plays a part to the findings of this mortality study. In all, it suggests that disabled people experienced poor living conditions and limited possibilities to participate in work and social life, which seem to have accumulated across life as evidenced by their low survival. Our descriptive results on the death causes indicate that disabled people were less exposed to infectious diseases than were the controls in the non-disabled group. A cautious interpretation is that the former group 'escaped' infections due to decreased interactions with others because disability made them subject to some 'lock-in' mechanisms, although the era of institutionalization did not occur in Sweden or the area under study until the early 20th century. This notion of isolation is further supported by the fact that disabled people rarely experienced violent deaths, possibly due to their low level of participation in the labor market, for example, or in society at large. Yet, it must be borne in mind that they ran far higher mortality risks than did the non-disabled.

Although our mortality findings indicate that disability brought health issues, the impairment per se cannot have immediately compromised people's lives or restricted their opportunities. It takes more to explain why disability promoted mortality. We think our results are not only or directly due to the impairment itself, but also to indirect effects coupled with socio-economic hardship and negative views in society that afflicted individuals with disabilities. Such surrounding circumstances and attitudes help explain the compromised life chances associated with disability, both in the past and today. 


\section{ACKNOWLEDGEMENT}

This study is part of a project headed by Lotta Vikström that has received funding from the European Research Council (ERC) under the European Union's Horizon 2020 research and innovation programme, Grant Agreement No. 647125, 'DISLIFE Liveable Disabilities: Life courses and opportunity structures across time', 2016-2021 (see DISLIFE website).

\section{REFERENCES}

Edvinsson, S. (1992). Den osunda staden: Sociala skillnader i dödlighet in 1800-talets Sundsvall (Doctoral dissertation, Umeå University).

European Commission. (2017). Eurostat disability statistics. Retrieved from https://ec.europa.eu/eurostat/ statistics-explained/index.php/Disability_statistics. Accessed August 21, 2020.

Haage, H. (2017). Disability in individual life and past society: Life-course perspectives of people with disabilities in the Sundsvall region of Sweden in the nineteenth century (Doctoral dissertation, Umeå University). Retrieved from http://urn.kb.se/resolve?urn=urn:nbn:se:umu:diva-130333

Haage, H., Häggström Lundevaller, E., \& Vikström, L. (2016). Gendered death risks among disabled individuals in Sweden. A case study of the 19th-century Sundsvall region. Scandinavian Journal of History, 41(2), 160-184. doi: 10.1080/03468755.2016.1155859

Schur, L., Kruse, D., \& Blanck, P. (2013). People with disabilities: Sidelined or mainstreamed? Cambridge: Cambridge University Press. doi: 10.1017/CBO9780511843693

United Nations (2020). Factsheets on persons with disabilities. Retrieved from https://www.un.org/ development/desa/disabilities/resources/factsheet-on-persons-with-disabilities.html. Accessed August 21, 2020.

Vikström, L., Häggström Lundevaller, E., Junkka, J., \& Haage, H. (2019). Ett annorlunda liv? Följder av funktionsnedsättningar i 1800-talets Sverige. In Funktionsnedsättning $i$ arbetsliv och välfärd: Rapport från forskarseminariet iUmeå 16-17 januari 2019 [A different life? Consequences of disabilities in 19th-century Sweden. Social Insurance Report 2019] (pp. 15-29). Försäkringskassan; Analys och prognosSocialförsäkringsrapport. Retrieved from http://urn.kb.se/ resolve?urn=urn:nbn:se:umu:diva-158809

Westberg, A., Engberg, E., \& Edvinsson, S. (2016). A unique source for innovative research: The POPLINK database. Historical Life Course Studies, 3, 20-31. Retrieved from http://hdl.handle. net/10622/23526343-2016-0003?locatt=view:master

World Health Organization. (2004). International statistical classification of diseases and related health problems (Vol. 1). World Health Organization. Retrieved from https://www.who.int/classifications/ classification-of-diseases. Accessed January 5, 2021. 